\title{
BREVE REFLEXÃO: EDUCAÇÃO, AUTORITARISMO E VIOLÊNCIA SOB A ANÁLISE DA TEORIA CRÍTICA FRANKFURTIANA
}

\author{
Cleudes Maria Tavares Rosa \\ Universidade Federal de Goiás (UFG), Goiânia, Goiás, Brasil
}

\begin{abstract}
Resumo: O presente artigo discute, a partir da Teoria Crítica frankfurtiana, especialmente em Adorno e Horkheimer, como a relação entre autoritarismo e violência implica uma simbiose na sua manifestação, demonstrada a presença de ambos na contemporaneidade, em que os aspectos subjetivos e objetivos deles mostram-se entrelaçados e presentes na sociedade administrada. Investiga-se a possibilidade de se alcançar alternativas para escapar de tal barbárie pela via da educação e da formação humana.
\end{abstract}

Palavras-chave: Autoritarismo. Violência. Educação. Formação humana.

Ao debruçarmos nosso olhar sobre a questão da violência, urge refletirmos sobre os aspectos constitutivos dela ao longo do processo histórico. Nesse sentido, a contribuição da Teoria Crítica da Sociedade, em específico os textos dos pensadores da Escola de Frankfurt Adorno e Horkheimer, tem muito a oferecer no sentido das críticas efetuadas, ao longo de suas obras, a respeito do projeto de humanização do homem.

No ensaio Dialética do Esclarecimento, em seu prefácio, a explicitação da preocupação é visualizada na análise sobre a sociedade capitalista, doravante denominada pelos autores como sociedade administrada, e pelo seguinte questionamento: "[ ...] por que a humanidade, em vez de entrar em um estado verdadeiramente humano, está se afundando em uma nova espécie de barbárie?" (ADORNO; HORKHEIMER, 1985, p. 11). 
Refletir sobre a violência é compreender que ela é elemento constituinte do humano. Esse humano, violento, centrou seu poder de destruição em direção à natureza e aos outros homens e intentou a dominação. É necessário, contudo, compreender que a violência é regressão, é negação da humanidade em si. A essa regressão, como manifestação de violência física, Adorno denomina barbárie (1995). O autor conceitua e identifica o sentido da barbárie, conforme Sílvia Zanolla, como:

objetivo, referido aos fatores e situações sociais que contribuem para a violência no âmbito estrutural, da ordem das relações produtivas e, nos aspectos humanos inerentes à constituição da subjetividade, o que envolve reconhecer fatores que dizem respeito à dinâmica psíquica dos indivíduos, à "sua alma", ou "espírito", no sentido filosófico da singularidade humana: seus desejos, necessidades, sentimentos e emoções (ZANOLLA, 2010).

No processo de dominação, esse indivíduo, sujeito de sua trajetória, intentou a autonomia. Constituiu um corpus de conhecimentos a respeito da natureza, no sentido de compreendê-la e dominá-la, e constituiu a cultura. Para a Teoria Crítica da Sociedade, a perspectiva subjetiva no processo de construto da cultura há que ser considerada. Esse indivíduo passou a limitar, a impedir seu exercício de liberdade pelos freios impostos pela cultura que ele próprio constituiu no primeiro momento da dominação da natureza, a sua própria natureza. Por conseguinte, a liberdade anterior vivenciada foi solapada, minada, pelo momento consentâneo, de sujeição da libido, da vontade, da busca do prazer, as quais passaram a ser controladas culturalmente e socialmente impostas. A cultura passou a subjugar os instintos humanos, sua libido, a satisfação irrestrita das suas necessidades. Tais necessidades foram, doravante, moldadas, recalcadas, contidas.

O conteúdo recalcado dessa libido, alerta Freud (1974), pode voltar à tona, uma vez que o processo cultural e social constituído centrou-se no recalque, na repressão e na luta todo o tempo contra a liberdade instintual buscada. Se essa liberdade instintual está contida pelo peso da cultura, a repressão, o recalque dos instintos, se dá no âmbito biológico e no histórico (a dominação é social e se desdobra em todos os indivíduos dessa sociedade, em nome da exigência tolerável por parte da cultura e da sociedade).

A Teoria Crítica da Sociedade se constitui a partir da discussão dos seus autores com dois referenciais, dentre outros (Kant, Hegel, etc.), que se complementam: o marxiano com a análise objetiva da sociedade e o freudiano com a subjetiva. Em Marx, o homem se humaniza pela mediação do trabalho na busca de satisfação de suas necessidades, que, uma vez satisfeitas, geram outras, constituindo o primeiro ato da história. A história do 
homem é a história da sua produção da vida, condicionados por organização corpórea e agrupados (MARX, 2002). Em Freud, o homem é animal e se humaniza na medida em que adia a satisfação e restringe a busca pelo prazer, transformando a atividade inicialmente lúdica (princípio do prazer) e passando a evitar a dor; é a luta da razão contra a não razão.

Em Adorno, ressalta-se a repressão do animal contido em si a favor da civilização e orientado pela razão. Adorno elabora, juntamente com Horkheimer, uma explicação sobre como a razão, ao longo do tempo, se degenerou em des-razão e efetivou a regressão do homem, em um momento no qual o processo civilizacional e tecnológico parecia tão avançado. É que, no processo de busca do conhecimento, o homem aprendeu com a natureza, dominou-a e dominou outros homens. Nesse sentido, "O que os homens querem aprender da natureza é como empregá-la para dominar completamente a ela e aos homens" (ADORNO; HORKHEIMER, 1985, p. 20). Nada mais foi considerado a não ser o narcisismo e a vaidade. Há que se falar em conhecimento, mas com ele há que se subjugar o outro, diferente, violentá-lo para que se submeta aos interesses do dominador.

Na obra Dialética do Esclarecimento, Adorno e Horkheimer (1985) tematizam o esclarecimento

como um processo de emancipação intelectual resultando, de um lado, da superação da ignorância e da preguiça de pensar por conta própria e, de outro lado, da crítica das prevenções inculcadas nos intelectualmente menores por seus maiores (HORKHEIMER; ADORNO, 1985, p. 7).

A autonomia deve ser entendida como esclarecimento, farol para a compreensão de processos sociais em que a violência se torna barbárie e leva à desumanização dos indivíduos. Essa barbárie é constituída pelos mecanismos de frieza, distanciamento, desconhecimento do outro: tais mecanismos são subjetivos.

Há que se considerar, necessariamente, os aspectos objetivos da sociedade capitalista, nos quais o mercado e o poder econômico estruturamse em torno das finanças e do consumismo. Na sociedade capitalista, as relações são organizadas semelhantemente ao mundo dos negócios. Nele, imperam sucesso e propriedades materiais como mecanismos de mensuração desse sucesso, pessoal e em relação ao outro, e a relação humana, na qual poderia ocorrer a emancipação, parece inexistir para essa sociedade instrumentalizada pelo lucro.

A cultura, como processo, é a mediação efetuada pelo indivíduo, entre ele próprio e a natureza. É possível distinguir, através da cultura criada 
pelos indivíduos, que estes renunciam à sua libido a favor das atividades expressas socialmente, que podem levá-los a se presumirem sujeitos; ou seja, é, também pela repressão dos instintos que a cultura se constitui (FREUD, 1974). Por essa negação determinada, o pensamento expressa a ausência de liberdade constituída pelos freios culturais. É possível, portanto, entender que a menoridade, a impossibilidade de refletir por si, é garantidora da permanência da violência enraizada e que tal processo, consequentemente, impede o indivíduo de entender-se como sujeito. Nesse sentido, é possível apreender a experiência formativa como "movimento pelo qual a figura realizada seria confrontada com sua própria formação" (ADORNO, 1995. p. 25). Ora, se tal sujeito é inapto para o exercício da reflexão, repete o comportamento baseado em atos violentos, agressivos. Essa repetição se estende como teia, constelação, e pode provocar processos de identificação. O conceito psicanalítico de identificação remete à "mais antiga manifestação de uma ligação afetiva de uma pessoa com outra" (FREUD, 2016). É que pensar a violência, na sua manifestação regressiva de força física, doravante denominada barbárie, implica pensar não apenas as condições objetivas nas quais esta se manifesta. É exigível também investigar subjetivamente os seus sujeitos. Segundo Adorno, "o fato de precisarmos nos conscientizar desse elemento desesperador [...] deve ir além dos pressupostos objetivos [...] é preciso buscar as raízes nos perseguidores" (ADORNO, 1995).

Em La personalidad autoritária, Adorno (1965) demonstra que o autoritarismo, sob a perspectiva psicológica, é a tendência geral a se colocar em situação de dominação ou submissão, em relação aos outros, como consequência da insegurança do "eu" ou medo de ser débil, ou por sentimento de culpa. Nessa perspectiva, o autoritário considera o outro como rival e, se este for considerado "superior", deverá ser temido; caso seja considerado "inferior", deverá ser dominado. Logo, o "autoritarismo significa uma predisposição defensiva a se conformar acriticamente a normas e movimentos do poder investido pelo sujeito de autoridade" (ADORNO, 1995, p. 5). É preciso observar o perfil do indivíduo autoritário, relacionando-o ao outro, ao diferente: a falta de sentimento, a indiferença e a frieza em relação ao outro; a identificação com o poder; a manifestação de um espírito destrutivo ou beligerante pela indiferença manifestada na intolerância e no preconceito; a máscara democrática quando o indivíduo é antidemocrático; o entender que o outro recebe algumas vantagens e que por ser compreendido e significado como inferior e diferente não deveria ter direitos que são considerados pelo autoritário como vantagens. Estas são, segundo Adorno (1995), características potenciais da personalidade fascista, autoritária. 
O autoritarismo deriva da ideia distorcida de que um líder deve ter presença marcante e ditatorial nessa sociedade, em que a discriminação social se torna uma das causas estudadas por Adorno, as quais foram potencializadas, mundialmente, pelo antissemitismo. A definição de autoritário na Teoria Crítica refere-se ao indivíduo de caráter "potencialmente fascista", que é dominado pelos fatores subjetivos, como o medo e a culpa, e por fatores objetivos e materiais em que a lógica, predominantemente capitalista, o sucesso, a superioridade social, econômica, de prestígio e étnica interferem nos embates e nos conflitos humanos em todas as esferas da sociedade.

Pensar a violência enseja pensar a dominação: doce, simbólica, pela via cultural e da indústria cultural, que uniformiza maneiras de pensar, agir, comportar-se e consumir: lazer, imposição de uma única língua, religião, padrão de economia alimentar e vestimenta, mediante a inculcação de um processo civilizatório etnocentrista, segundo o qual os símbolos de distinção só podem ser alcançados por todos mediante essa padronização e pelo pragmatismo que marca a sociedade administrada. E, com a dominação como manifestação da força bruta, barbárie, na qual "a regressão à violência física primitiva" (ADORNO, 1996), e sem vinculação aparente a objetivos racionais, senão aos ditames irracionais contidos nas representações e identificações inculcadas pela vertente da violência doce ou simbólica acima elaborada. Ambos os processos conduzem à coisificação do outro, daquele que é julgado diferente.

O processo de coisificação, conforme Adorno (1995), inicia-se com a ideia de severidade, no equívoco interpretativo da virilidade como resistência à dor. Ao se entender rijo, duro, capaz de suportar dores, físicas ou emocionais, o indivíduo se compreende e se explica como coisa e passa a ter expectativas e cobranças de que o outro também o seja, coisificando-o. Aquele que nega tal processo de coisificação, em si e no outro, exercita sua humanidade. Contrapor-se aos pressupostos objetivos, sociais e políticos geradores de eventos semelhantes a Auschwitz, à barbárie, são difíceis. Adorno (1995), ao contrapor-se a história deduzida dos conceitos universais, se propõe a resgatar a história na qual as cicatrizes do sofrimento causado ainda estejam presentes, visíveis. Para tanto, explica que as tentativas de se contrapor a uma repetição de eventos danosos, semelhantes a Auschwitz, deverão se alicerçar na perspectiva subjetiva. Afirma ser cético aos apelos à religião, chamando por lucidez, posto compreender que se deve buscar nos algozes o tanto de frieza, de indiferença e incapacidade de amar, de identificar-se com o outro, diferente, que esses portam. E pondera ser necessário fazer o giro para o 
sujeito, ou a inflexão para o sujeito, ou seja, deve-se buscar compreender os mecanismos que tornam esses sujeitos capazes de matar. Compreender, no sentido de poder impedi-los. Verificando-se, ademais, que os culpados são todos os desprovidos de consciência e que se voltaram com ódio e fúria agressiva àqueles que se contrapuseram ao seu entendimento de mundo. Ao longo do tempo, a violência e o autoritarismo, com toda a sua força, foram se manifestando na sociedade administrada.

O autoritarismo manifestou-se considerando o outro como "inferior", que precisava ser subjugado pela força, pela barbárie que se manifesta nessa modelagem do outro, do diferente, ao padrão esperado; ou, docemente, pela legislação que se impõe pelo poder de polícia do Estado (WEBER, 1982 apud TAVARES ROSA, 2002). Nas relações autoritárias, ocorre repetidamente a repressão do diferenciado para a continuidade e a homogeneidade da sociedade administrada. $\mathrm{O}$ autoritarismo, expresso pelo autoritário, sequer pode ser por ele reconhecido. É preciso questionar a formação desses indivíduos autoritários na sociedade administrada, na qual o cálculo e a previsão se consolidaram.

A adesão cega à coletividade em um processo de identificação sem autorreflexão crítica revela de certa forma a barbárie e a "consciência coisificada", em que os indivíduos se identificam com o objeto, se alienam e se adaptam à coisa, ao objeto de desejo, sem o esclarecimento necessário para a compreensão dos fatos, pois "permanece cega frente a tudo o que veio-aser, frente a toda a compreensão da própria racionalidade, e absolutiza o que é-assim" (ADORNO, 1995, p. 118). Esse tipo de consciência produz a frieza em relação ao outro. A intensificação da divisão social do trabalho - e, com ela, a tecnologia gestada pelo trabalho intelectual e concretizada materialmente - potencializou o distanciamento entre os homens, viabilizando o isolamento social e o preconceito sobre toda forma de ser e de expressão do diferente, anteriormente estabelecidos pelos meios de comunicação de longo alcance, a indústria cultural. Esse processo levou à regressão e à exclusão da possibilidade do esclarecimento como possibilidade de menoridade e preguiça de pensar por si (ADORNO; HORKHEIMER, 1985) e sustentou a reificação, posto que os indivíduos se alienem cegamente, sem o poder de manifestação contra a barbárie social.

Pensar a barbárie e o autoritarismo implica, também, refletir sobre as condições sociais objetivas. Ambos, o autoritarismo enraizado e a violência, exigem a análise de como os sujeitos da história têm refletido e reproduzido materialmente as suas manifestações: é pensar a educação e a formação humana. 
Interessa aqui entender o porquê da continuidade do autoritarismo e da violência. E retornamos às explicações da Teoria Crítica de Frankfurt, especialmente Adorno e Horkheimer, ao discutirem os fundamentos do esclarecimento e as suas possibilidades de conduzir a sociedade rumo à humanidade.

Se a violência é parte constitutiva da porção animal do homem, desde o princípio, ela se manifestou na sua luta pela satisfação de necessidades e foi pela domesticação via trabalho que tais satisfações foram constituídas. O homem interferiu na natureza e a dominou, dominou outros homens e, no processo, urgia explicar os fenômenos naturais. Nessa explicação, pela mimese, era necessário ainda constituir freios culturais e morais para os demais, conduzindo-os à domesticação dos instintos e ao princípio de realidade. Foi pelo mito que se objetivou as forças da natureza e, mimeticamente, por ele se regulou o comportamento e se reduziu a angústia diante do desconhecido. Adorno e Horkheimer (1985) apontam que, pela relação anterior de submissão, pela mimese, o homem pretendeu e explicou os fenômenos, instrumentalizando a razão. Esta passou a ordenar a marcha rumo à dominação.

Essa violência se constitui como simbólica, não o sendo totalmente, no momento em que Ulisses, para ouvir o canto das sereias, amarra a si e tapa os ouvidos dos remadores: são dois momentos de violência. O primeiro, domesticando pela força sua porção animal que poderia se enredar pelos sentidos. Arrisca-se, posto que essa violência praticada contra si pode levá-lo a sucumbir ao interesse e se perder, ou não. A ela denomina-se aqui de violência doce, conquanto o ato materializado seja de agressão ao corpo, já desprezado no processo de compreensão do mundo e da vida. A prevalência explicativa estava ainda centrada no mito, separada do sujeito que agia em busca do conhecimento. $O$ segundo momento é a violência material, regressiva, contra o outro, o remador, diferente de Ulisses, o sujeito do conhecimento. A este, as amarras, a submissão, a manipulação, a violência física, materializada e doravante constitutiva do processo de administração da sociedade, a barbárie.

Se Ulisses é o sujeito do conhecimento e impinge a si mecanismos de controle racionais, o processo de conhecimento avançará desconsiderando a violência que esse sujeito vai impor a si, ao seu corpo, para conhecer e explicar o anteriormente explicado pelo mito. Agora, separado, fracionado apenas em razão, é que a desconsideração da sensibilidade torna-se realidade, materializa-se. Essa perda da sensibilidade configura o que Adorno denominou personalidade autoritária (1965). Objetiva-se compreender e explicar a exacerbação da violência; e, com ela, o autoritarismo manifesto e 
enraizado na contemporaneidade e as possibilidades de sua superação pela formação humana e pela educação.

A semiformação' e a educação são presentes no capitalismo tardio: nele, o Estado mínimo e a imposição da escola administrada; nela, a técnica e seus conteúdos hipervalorizados. Portanto, atenta-se para o alerta feito por Adorno: "Não é a técnica o elemento funesto, mas o seu enredamento nas relações sociais, nas quais ela se encontra envolvida" (apud COHN, 1986, p. 69).

Há um entrelaçamento de sentidos quanto ao processo formativo e à educação, em termos de uma racionalidade produtivista, que altera o que seja a ética em tais processos: formação e educação a partir do contexto econômico prevalente no capitalismo tardio e na sociedade administrada.

Essa crise de formação está expressa, segundo Adorno (1986), entre o trabalho e a formação. No ensaio Capitalismo tardio ou sociedade industrial, o autor aponta o crescimento e a conversão do uso da ciência e tecnologia como forças produtivas, fenômeno que levou, por consequência, a uma crise da formação e da educação, posto que as condições de produção econômicas e sociais a partir da implantação da social-democracia ou Welfare State, após a barbárie de Auschiwtz, deram continuidade, e ampliaram-na, à manipulação da população através da expansão do consumo, com a agudização do entrelaçamento entre economia e educação, através da indústria cultural.

A Teoria Crítica aponta que a formação cultural consistiria na experiência de formações entre "a filosofia da vida" entrelaçada a contextos amplos, arte, fatos históricos. Salienta que as reflexões dessas relações assim estruturadas não impedirão ou romperão o nexo entre o objeto analisado e a reflexão em curso (ADORNO, 2006). A formação cultural há de ser adquirida por esforço e por interesse, pela "capacidade de se abrir a elementos do espírito apropriando-as do modo produtivo na consciência, em vez de se ocupar com os mesmos unicamente para aprender conforme prescreve um clichê" (ADORNO, 2006, p.64).

A indústria cultural foi constituída no contexto do capitalismo avançado, no final do século XIX e no início do século XX, com a criação dos meios de comunicação de massa e o aumento da produção e da diversificação de mercadorias. Os Estados Unidos da América despontam como o propulsor, o introdutor da linha de produção padronizada, que barateou as mercadorias.

Nesse período, o rádio, o cinema, a fotografia e outras tecnologias midiáticas revolucionaram a comunicação e o entretenimento, com transmissões culturais, comerciais, religiosas etc. Nesse contexto, as guerras mundiais ocorreram, e a indústria do entretenimento em massa foi utilizada como instrumento de divulgação ideológica, de falseamento de uma 
realidade barbarizada pela violência, pela indiferença e pelo abandono de valores em prol dos interesses de dominação e econômicos.

O momento que antecedeu as duas grandes guerras foi de acumulação para alguns e desesperança para outros. Ao final da Primeira Guerra, o vazio e a desesperança deixados por ela não arrefeceram o caráter objetivo da dominação e ocorreu a Segunda Guerra. O esperado subjetivamente era que as nefastas experiências levassem ao questionamento, por parte da população, a respeito da destruição. Adorno (1985) salienta, com suas reflexões, não bastar buscar a justificativa para tais atos a partir de explicações subjetivas, psicológicas, religiosas ou de direito natural. Antes é preciso procurar as explicações nos algozes, os que ambicionam a dominação. Por isso, é exigido fazer o giro para o sujeito.

Pensar a relação autoritarismo e violência e/ou vice-versa enseja pensar as explicações teóricas a respeito da correlação entre a manifestação presente nesses fenômenos e que podem ser compreendidas a partir de qual método foi usado no percurso do conhecimento para a sua apreensão e sua explicação. Em uma explicação repetitiva e histórica, o método aplicável em toda a parte é entendido e explicado como confiável, pois renunciou à relação como a coisa, com o objeto do conhecimento. Esta é a forma prévia da teoria do conhecimento. O método, o "caminho" regulado, é uma consequência legítima de um anterior, pois, quando se pensa metodologicamente, também se exige algo primeiro para que o caminho não se interrompa e não termine em mero acaso. O procedimento é planejado, nada pode alterá-lo, é metódico e leva a certezas. Para Adorno (1995), a objetividade se deduz do arbítrio subjetivo e seu caráter fechado é a ruptura, a aparência de reconciliação e, por isso, o absoluto.

Não existe, para o método positivista, tensão entre o sujeito de conhecimento e o objeto a ser conhecido. Contrariando o ideário positivista que exige a relação mecânica e abstrata entre sujeito e objeto, Adorno (1995) afirma que nada pode ser extraído pela interpretação que, concomitantemente, não possa ser introduzido pela interpretação. $O$ sujeito é parte integrante do processo de conhecimento e este, por sua vez, não se reduz à simples análise e à decomposição em partes do real, mas, antes, é encarado como interpretação. Nesse sentido, não há separação entre autoritarismo e violência, o que possibilitaria sua compreensão não como derivação recíproca, pois, doravante, estaria assentada na perspectiva da formação humana constituída a partir de um processo de educação no sentido de constituição da autorreflexão crítica (ADORNO, 1995). Antes, contudo, é exigível buscar compreender e reconhecer os mecanismos que 
tornam a frieza, a indiferença, o desprezo em relação ao outro, diferente, não só como objetivo de conhecimento, mas mecanismo de despertamento de consciência nos autoritários, os quais dirigem sua fúria agressiva e ódio contra o outro. Para tanto, a dialética possibilitaria o revirar da compreensão na contraposição explicativa para a ausência dessa consciência de respeito pelo diferente que se constituiu através dos mecanismos simbólicos presentes na sociedade administrada.

A dialética consistiria num processo relevante para que o sujeito não se desvencilhe seja do trabalho reflexivo, seja do trabalho prático, tanto de apreensão como de reconhecimento acerca da insuficiência do pensamento diante da complexidade do real. Com efeito, ao tornar inseparáveis e contraditórios teoria e práxis, a dialética possibilitaria o exercício do pensamento, o tensionamento, a ruptura com a superficialidade, ou seja, com o senso comum.

Adorno entende que a intentio recta do sujeito cognoscente define-se a partir de sua valorização da ética do sujeito. Kant, na Crítica da razão prática (2007), elabora e discute o que seja a crise da ética. Adorno, no momento que denomina de confronto entre sujeito e objeto, configurando um realismo ingênuo, aponta que não havia vontade da mudança, mas que a visão ingênua dos valores desse sujeito foi abstração falsa e momento de constituição da coisificação da consciência, que sem autorreflexão se objetificou. Para alterar, é preciso fazer a virada para o sujeito, momento em que a primazia do objeto é alcançada e o sujeito se constitui objeto em sentido qualitativo radical e distinto do objeto. Esse objeto, ao ser conhecido pela consciência, é também sujeito. Sendo o sujeito o núcleo da mediação, da alteridade, da conciliação nos e pelos extremos, torna-se como o objeto e nunca o postulado por qualquer representação equivalente ao conceito de sujeito. A primazia do objeto não é intentio recta, maneira linear de olhar o objeto, é, sim, intentio oblíqua da intentio obliqua, multiplicidade de maneiras de olhar pela multiplicidade de ângulos de olhares para apreender o objeto em sua manifestação. As qualidades subjetivas do objeto, suas determinações, não devem ser desconsideradas e são pela exigência de sua continuidade que se afirma a primazia do objeto. Só é possível falar da primazia do objeto quando essa primazia em relação ao sujeito é determinada.

A possibilidade de constituição dessa alteração de olhar, conscientização em relação ao outro, diferente, é possível pela educação. Adorno aborda a questão em Educação após Auschwitz (1995), apontando que ocorre na primeira infância o momento fundante do caráter. É esse o momento constitutivo da formação humana, no ensejo de tentar evitar que 
a barbárie não se perpetue. Não será apenas a educação escolar que deve ser reconhecida no processo de formação do caráter não autoritário, deve-se levar em conta o papel da autoridade no seio da família, na primeira infância.

Crochik (1990), ao discutir a relação entre a ideologia da racionalidade tecnológica e a personalidade narcisista, retoma a discussão efetuada por Adorno e Horkheimer (1978) quanto à submissão da personalidade à ideologia autoritária, compreendendo que esse processo ocorre devido ao enfraquecimento da família, ao afastamento, ao enfraquecimento da figura paterna como autoridade no momento de formação do Ego e do Superego do indivíduo. Tal afastamento, ou enfraquecimento, possibilitou uma menor identificação com a autoridade, permitindo-se a repetição, a imitação, a mimese e anulando a contestação diante da irracionalidade das forças objetivas manifestas na sociedade administrada. Nesta, a pressão social civilizatória, a cultura, impõe-se de maneira insuportável, obrigando o indivíduo ao tensionamento entre o princípio do prazer e o princípio de realidade (FREUD, 1974) e exigindo, segundo Adorno, que esse sujeito, incapaz de escapar à sensação de impotência e claustrofobia gerada pela sociedade administrada e sua cultura, dirija sua violência, o tensionamento entre os princípios de autopreservação e autodestruição, ao outro, aos socialmente considerados fracos, "felizes", tendendo, portanto, a destroçá-los.

É nesse momento fundante da constituição desse tensionamento psíquico de aceitação ou repressão em relação ao outro que a educação propiciará a autodeterminação: a desbarbarização poderá ocorrer a partir da educação na primeira infância, através da mediação pelo princípio da autoridade que, ao renunciar a comportamentos autoritários, possibilitarão a formação de superegos rigorosos, estáveis, exteriorizados (ADORNO, 1995), efetuada por autoridades que não se imponham barbaramente, sejam elas autoesclarecidas, sejam elas transparentes na sua manifestação, negando a rudeza, o grito, a palmada (violência física perpetrada contra o mais fraco, a criança). Tais decisões manifestam autonomia no pensar, pois críticas à manifestação da violência e à perpetuação do autoritarismo poderão despertar vergonha e constrangimento "acerca da rudeza existente no princípio da cultura" (ADORNO, 1995, p. 165) e propiciarão mudanças, ainda que lentamente, nos indivíduos, e estes caminharão no sentido da humanização.

Esse movimento é lento; todavia, poderá levar à emancipação. Alcançar a emancipação requer a saída da menoridade, da falta de coragem e de decisão de pensar o próprio pensamento. Assim, para pensar a formação como autonomia, requer-se não apenas a formação técnica, mas a formação 
cultural que, conforme Adorno (1995), deveria consistir em experiências mais amplas entre a filosofia da vida e as artes, o amor, o esforço espontâneo, a disposição para abrir-se a elementos do espírito. Aí poder-se-ia alcançar o que seja uma educação como consciência em relação ao conteúdo, às formas e às estruturas de pensamento do sujeito, daquilo que ele é ou não. $E$ tal consciência levaria à experiência, que é emancipação.

Artigo recebido em: 16/04/2018 Aprovado para publicação em: 28/06/2018

BRIEF REFLECTION: EDUCATION, AUTORITARISM AND VIOLENCE UNDER THE ANALYSIS OF THE FRANKFURTIANA CRITICAL THEORY

ABSTRACT: Starting from the critical frankfurtian theory, especially in Adorno and Horkheimer, the present article discusses how the relation between autoritarism and violence implies symbiosis in its manifestation, demonstrated the presence of both in contemporaneity, in which the subjective and objective aspects of them are entwined and present in the administered society. Investigate the possibility of reaching alternatives to escape from this barbarism by way of education and human formation. KEYWORDS: Autoritarism.Violence.Education.Human formation.

BREVE ANÁLISIS: EDUCACIÓN, AUTORITARISMO Y LAVIOLENCIA UNA ANÁLISYS SOB LATEORÍA CRÍTICA FRANKFURTIANA

RESUMEN: El presiente artículo discurre La partir de La teoria crítica frankfurtiana, em específico Adorno e Horkheimer, como larelación distinguida por El autoritarismo y La violência implica simbiosis em La manifestación, probadala presencia em ambos em lacontemporanedad em lo que El aspectos subjetivos e objetivos de essas sónentrelazados y acuales em lasociedadconducida. Indaga lapossibilitad de ser alcanzadoel cambio para elescabulirsela barbárie por loscamiños de laeducación y por laformación humana.

Palabras-Clave: Autoritarismo. Violencia. Educación. Formación humana. 


\section{NOTA}

1 No Brasil, existe a discussão no meio acadêmico acerca desse conceito de Adorno, em alemão, Halbbildung, e traduzido como semiformação e pseudoformação. De acordo com Neuvald e Guilhermeti (2006, p. 2), "Halbbildung é um termo alemão formado pela justaposição das palavras Halb (que pode significar meio, metade ou pseudo) e Bildung (que significa, ao mesmo tempo, cultura, formação cultural, formação da personalidade ou educação num sentido amplo). No entanto, Halbbildung não pode ser simplesmente traduzido por meia formação ou falsa formação, pois Adorno imprime um sentido dialético ao termo, no qual, simultaneamente, indica falsidade ou limitação do processo formativo, quando este perde sua articulação entre autonomia e dominação; mas também indica uma formação real e efetiva, apenas como dominação. Por isso, semiformação é um termo que vem sendo mais utilizado pelos tradutores, como Maar (1992), Pucci, Zuin e Ramos de Oliveira".

\section{REFERÊNCIAS}

ADORNO, T.W. La personalidade autoritaria. Buenos Aires: Editorial Proyección, 1965. Educação e emancipação. Tradução Wolfgang Leo Waar. 4. ed. Rio de Janeiro: Paz e Terra, 2006. . Palavras e sinais: modelos críticos. 2. ed. Petrópolis, RJ: Vozes, 1995. .; HORKHEIMER, M. Dialética do Esclarecimento.Tradução Guido Antonio de Almeida. Rio de Janeiro: Jorge Zahar, 1985.

CROCHIK, J. L. A personalidade narcisista segundo a escola de Frankfurt e a ideologia da racionalidade tecnológica. Psicologia - USP, São Paulo, v. 1, n. 2, p. 141-154, 1990. FREUD. S. O mal-estar na civilização. Rio de Janeiro: Imago, 1974. .Psicologia das massas e análise do eu. São Paulo: Companhia das Letras, 2016 KANT, I. Crítica da razão prática.Tradução de J. Rodrigues de Merege. São Paulo: Acrópolis, 2007. Disponível em: www.marxist.org. Acesso em: 13 set. 2017.

MARX, K. A ideologia alemã. São Paulo: Martins Fontes, 2002

NEUVALD, L.; GUILHERMETI, P. A semiformação no curso de Pedagogia: uma reflexão introdutória. In: SEMINÁRIO NACIONAL DE FILOSOFIA E EDUCAÇÃO - CONFLUÊNCIA S, 2, 2006, Santa Maria. Anais... Santa Maria: Facos, 2006. Disponível em: <http://coral. ufsm.br/gpforma/2senafe/PDF/026e4.pdf>. Acesso em: 11 abr. 2016.

TAVARES ROSA, C. M. Ronda: o discurso político sobre a criminalidade urbana violenta no contexto de uma sociedade autoritária. 2003. 172 f. Dissertação (Mestrado) - Programa de Pós-graduação em Sociologia, Universidade Federal de Goiás, 2003.

ZANOLLA, S. R. Teoria crítica, cultura e educação. Educação, cultura e formação. O olhar da filosofia. Goiânia: Ed. PUC, 2009. 
ROSA, C. M. T.

Educação e barbárie: aspectos culturais da violência na perspectiva da teoria crítica da sociedade. Sociedade e Cultura, Goiânia, v. 13, n. 1.

Cleudes Maria Tavares Rosa: Graduada em Ciências Sociais (UFG) e Direito (PUC-GO), especialista em Direito Civil (Uniderp), mestre em Sociologia e doutoranda em Educação (UFG) e advogada (OAB GO 42550).

E-mail: cleudestavares@gmail.com 